\title{
Perceptions on safety climate: a case study in the Omani construction industry
}

1 Tariq Umar MSc, CEng IntPE (UK), MICE PhD candidate, London South Bank University, London, UK: Lecturer, College of Engineering, A'Sharqiyah University, Ibra, Oman (corresponding author: tariqumar1984@gmail.com)
2 Charles Egbu PhD, FRICS, FCIOB, FAPM, FRSA, FHEA Dean, School of the Built Environment and Architecture, London South Bank University, London, UK
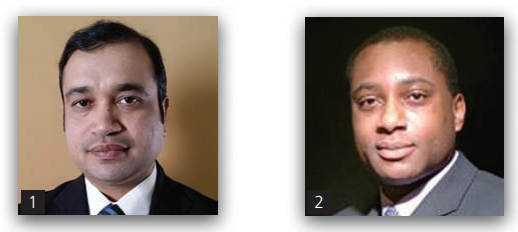

Generally, a mature safety climate and a rich safety culture contribute to achieving a safe workplace. The purpose of this paper is to examine the understanding of using safety climate and to make explicit some of the main elements that have a greater impact in the construction industry in Oman. Relevant safety climate factors from literature have been identified using specific search criteria, which resulted in 62 factors spanning over a period of 37 years from 1980 to 2017. The results of face-to-face interviews with construction professionals from chosen construction companies in Oman that show a high level of safety performance are also presented. The result shows that management commitment; alignment and integration of safety as a value; accountability across the board; supervisory management; empowerment and involvement of workers; improvement of communication; and training and education are some of the main elements that significantly affect safety climate in Oman. The common safety climate factors reported in this research are based on the views of selected interviewees working in the construction industry in Oman. It is suggested that these factors may be validated further considering views of other members of the construction team, before being used for safety climate assessment.

\section{Introduction}

The International Labour Organization data for the year 2015 reveals that every year, more than 100000 workers die on construction sites due to different occupational safety and health (OS\&H) conditions. This number is nearly $30 \%$ of all occupational deadly injuries. Different statistical data reveal that construction labourers in different developed countries are three to four times more likely to die from accidents on-site compared to workers in other industrial sectors. In the developing world, there is a higher risk (three to six times more) of death linked with construction work than in developed countries (ILO, 2015). Many construction workers suffer and die from workrelated illness developed from prior influence of dangerous materials, such as asbestos and other chemicals. The construction industry is among the world's major industrial sectors; it includes subsectors such as building, civil engineering, demolition and maintenance. It is reported to make up a considerable percentage of the gross domestic product in different countries - for instance, $6 \cdot 10 \%$ in the UK, $5 \cdot 50 \%$ in Japan and $9 \cdot 0 \%$ in Oman (NCSI, 2017; ONS, 2017; SHJ, 2017). Statistics published by the Oman Society of Contractors in 2016 show that the total number of residents working in this industry was 738593 (OSC, 2016a). Current and planned development projects in various sectors in Oman, including construction, for the financial year 2015-2016 are shown in Figure 1. Projects in the construction sector stand out as having the largest value: US $\$ 43 \cdot 16$ billion. According to the budget report, spending on development projects is estimated at US $\$ 3 \cdot 12$ billion ( 1.2 billion OMR), representing the amount to be paid during the year 2017, as the actual work progresses (OB, 2017).

The construction industry is growing rapidly in different developing countries and is thus recognised as a main source of jobs to different labours (Duranton, 2015; Umar and Wamuziri, 2016a). However, at the same time, it is recognised as one of the risky industries. Construction workers' jobs may include a variety of tasks while they are working in different projects. These projects may be related to building; repair and maintenance; renovation and demolition; transportation including construction of highways, bridges and airports; and projects related to docks and harbours. Construction workers are expected to be open to different types of risks during their work, such as dust and condensation, stiff working situation, handling heavy load, hot climatic conditions, working at heights, excessive noise, vibration and heavy machinery, and different chemicals. Different causes of accidents and illnesses in the construction sector are well projected by many researchers and can thus be prevented (ILO, 2015). Umar and Wamuziri (2016a) noted that, officially, there are no statistics in Oman as to how many construction workers were injured at work. However, data from ten reputable construction organisations show that in 2014, more than 3500 construction workers received medical treatment due to work injuries. Due to 


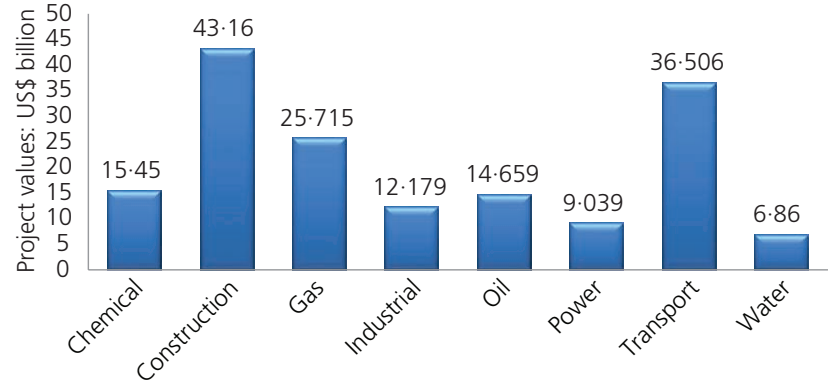

Figure 1. Values of ongoing and planned projects in different sectors of Oman (Deloitte, 2015)

the severity of injuries, around $10 \%$ of these workers were hospitalised. The report further reveals that roughly $18 \%$ of these workers, who were hospitalised, later died at their work or in hospital. In comparison to the previous year's data, the number of injured workers rose by 246. For various reasons including reputation, company owners hesitate to publicise such information. Umar et al. (2018), while quoting the data from the Public Authority of Social Insurance in Oman (PASI), observed that the expenditure related to OS\&H rose from 1 million OMR (= US\$2.6 million) in 2012 to 2.9 million OMR (= US\$7.53 million) in 2016, as shown in Figure 2. It is also important to note that only Omani citizens are eligible to register in the PASI system, despite the fact that only $8 \%$ of citizens work in the construction industry in Oman (OSC, 2016b). Foreign workers in construction and other industries are insured under a private insurance scheme in the country.

In Oman, the majority of construction workers are foreigners, representing more than $90 \%$ of the total workforce in this industry. These workers are, however, not insured under the government agency scheme (NCSI, 2015). As per the law of the land, construction organisations need to pursue private insurance for their workers. Since the risk connected with construction workers is huge, the insurance premium for workers in construction is relatively more than those workers in other sectors. Construction contractors further carry high expenses at the time of hiring and pay for repatriation, compensation and replacement in

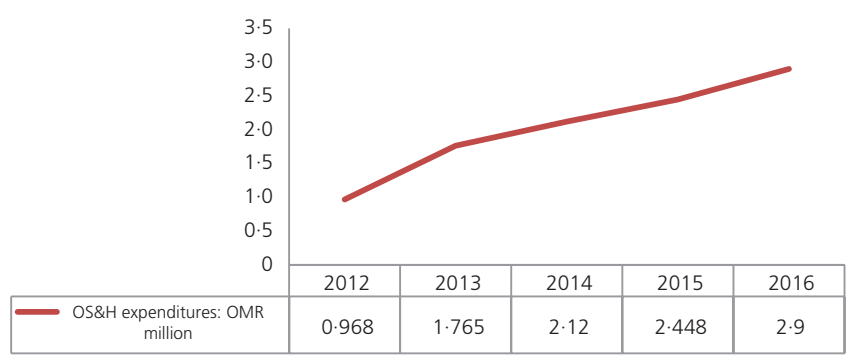

Figure 2. Increase in OS\&H expenditure in Oman (Umar et al., 2018) case of accidents resulting in injuries and fatalities (Dube et al., 2010).

The appreciation and importance of administrative, managerial and social factors for safety performance has increased in the last two decades (Kines et al., 2011). Safety climate is a subgroup of the organisational climate providing a direction for safety management, complementing the frequently predominant engineering path. James and Jones (1974) viewed safety climate as an individual attribute as opposed to an organisational attribute. Zohar (1980) mentioned that the safety climate mirrors employees' understanding about the comparative significance of safe performance in their job-related behaviour. An understanding of the safety climate elements can be helpful in improving the safety performance of a construction organisation. Although long-term studies are relatively few, there is an increasing sign that safety climate is a precursor of safety performance (Clarke, 2010, 2006; Kines et al., 2011; Kuenzi and Schminke, 2009; Larsson et al., 2008; Neal and Griffin, 2006; Nielsen and Mikkelsen, 2007; Pousette et al., 2008; Wallace et al., 2006; Zohar, 2002). Additionally, safety climate findings are regarded to be more precise (e.g. multisliced) and are proactive for improving safety, rather than reactive (after the fact) data from accident numbers and accident and incident investigations (Seo et al., 2004). The focus on elements that impact safety and safety improvements within organisations has been shifted in the last century. Hale and Hovden (1998) define three periods of safety that includes the technical period (1920s), the human factor period (1970s) and the management system period (1980s). The third period of safety spread the focus to include safety culture; the approach of safety culture was accurately presented and delineated after the Chernobyl accident, which took place in 1986 (INSAG, 1992). Thus, enthusiasm for the safety culture approach has increased as safety researchers and practitioners have been solicited to characterise and operationalise this approach. Also, increasingly, the two terms 'safety climate' and 'safety culture' have been confused (Glendon and Stanton, 2000; Hale, 2000). Although differences do exist, safety culture and safety climate are the approaches that have attracted more concentration across a broad number of industrial businesses including construction (Clarke, 2000). One of the reasons for this is that a rich safety culture and a mature safety climate are considered among the most important elements in attaining a safe workplace (Bergh et al., 2013). To enhance the level of safety culture and safety climate, it is crucial first to gauge the existing level of safety culture and safety climate; then agree what level of safety culture and safety climate is required, obtainable and desired; and then make strategies to accomplish the desired safety culture and safety climate (AIChE, 2012).

Safety climate can be defined as common understandings between the employees of a social unit of policies, procedures and practices connected to safety in a business (Kines et al., 2011). The Centre for Construction Research and Training (CPWR) defined 'safety climate' as workgroup members' common thoughts of management and workgroup safety-related policies, procedures and practices (CPWR, 2014). Similarly, Zohar (1980) described safety climate as a view of 
workers' understandings about the respective significance of safer acts in their work-related behaviour. There are several definitions of safety culture endorsed by researchers; however, the Cox and Cox (1991) definition appears to be more concise and simple. They described safety culture as attitudes, beliefs, understandings and values that employees contribute in connection to safety. Scientists and experts have established safety culture and safety climate as a fundamental element in curtailing injuries, illnesses and deaths at workstations. Many construction organisations are trying to enhance safety climate gauges as a way to step closer to the target of obtaining zero-accident workplaces (CPWR, 2013). This paper presents a review of using the safety climate approach to enhance safety performance along with the results of a semistructured interview conducted in Oman. A recent safety climate assessment questionnaire developed in 2011 by a group of researchers from Nordic countries consists of 50 questions on different elements of safety climate related to management and workers. The management factors include safety competency, commitment, priority, empowerment and justice. The workers' factors consist of safety commitment, prioritising safety, non-acceptance of risk, learning and trust on coworkers' safety competency. Common factors such as effective safety communication and confidence in the efficacy of safety management systems are related to both management and workers (Kines et al., 2011).

\section{Literature review}

Umar (2016) expressed that costs of accidents in construction in Oman would be comparatively more than those in the USA and UK, considering the fact that the construction industry, in terms of maturity and safety performance, is not as developed as those in the USA and UK. The reports published in a single newspaper in Oman, spreading over a period of 6 months from 1 May to 30 November 2015, reveal that a total of nine workers were killed and more than 25 were injured in accidents that took place at different construction sites. The actual number of death and injuries during this period could be more as data published in the newspaper may not include the accidents that may have occurred in a remote area or those where the numbers of injuries were fewer and thus did not attract the focus of the newspaper. The costs of accidents in construction in Oman reported by Umar (2016) is estimated at US\$3.237 billion (based on the total value of construction projects), while the compensation costs are approximately US\$3.74 million/year. There are challenges for safety in construction in Oman, but opportunities do exist. Safety regulatory organisations such as the Occupational Safety and Health Administration in the USA and the Health and Safety Executive (HSE) in the UK have played significant roles in improving the safety performance in their jurisdictions. Statistics indicate that worker deaths in America were reduced, from nearly 38 deaths per day in 1970 to 12 per day in 2014. Similarly, the number of worker injuries and illnesses declined from 10.9 incidents per 100 workers in 1972 to 3.3 per 100 workers in 2013 (OSHA, 2014). The national framework for safety improvement in Oman presented by Umar and Wamuziri (2016a) involves all stakeholders under a regulatory organisation, as shown in Figure 3. Some researchers claim that small and medium construction organisations have a low capability to comply with safety regulations or they need to bear a high cost for this, which results in less financial benefits (Lancaster et al., 2003; Tang et al., 2004). The results of the research conducted by Ikpe et al.

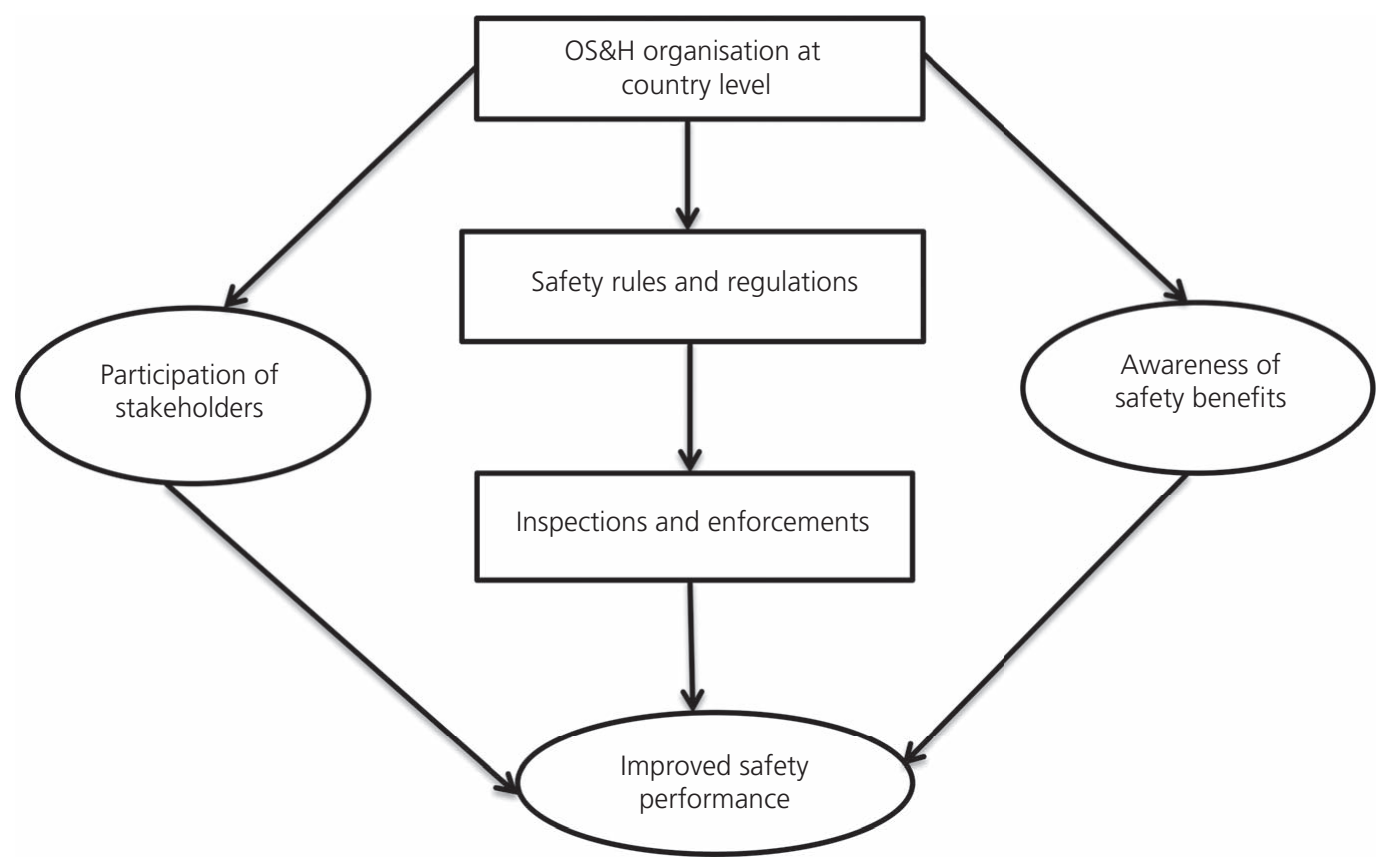

Figure 3. Safety model for construction (Umar and Wamuziri, 2016a) 
(2012) in the UK shows that the argument that construction organisations have very low capability and financial benefits from improved safety performance is no longer valid. The results of a cost-benefit analysis affirmed that when the total costs of accident prevention were matched to the total benefits of accident prevention, the profits far exceed the costs of accident prevention by a ratio of nearly $3: 1$. This means that when contractors, regardless of their sizes, spend $£ 1.00$ on accident prevention, they gain $£ 3.00$ (Ikpe et al., 2012). The approach describing the use of safety climate factors to improve safety performance is shown in Figure 4 (Umar and Wamuziri, 2016a).

The management's commitment towards safety has been regarded as a main element for improving safety performance. Zohar (1980) concluded that the senior management's engagement in safety and programming safety issues are two separate subjects. Similarly, Flin et al. (2000), while determining typical attributes for the assessment of safety climate, established that perceptions of management safety commitment and priority are the most commonly appraised factors in safety climate research. Apart from management commitment, Clarke and Ward (2006) noted that the workgroup is the most influential in the socialisation of new members in the group of organisation and recommended that understandings of workgroup norms are highly influential for group safety climate. Similarly, Hofmann and Morgeson (1999) urged that management boosting open communication on safety delivers a firm message on how safety is admired. Jeffcott et al. (2006) noted the significance of learning for a constructive safety culture through regular meeting, analysing and propagating information in an environment valuing expertise and being based on trust, where workers can classify and have the willingness to convey unusual acts and mistakes. Cox et al. (2006), while discussing the trust in high-reliability institutions, concluded that

Assessment of current level of safety climate leading factors through safety climate questionnaire

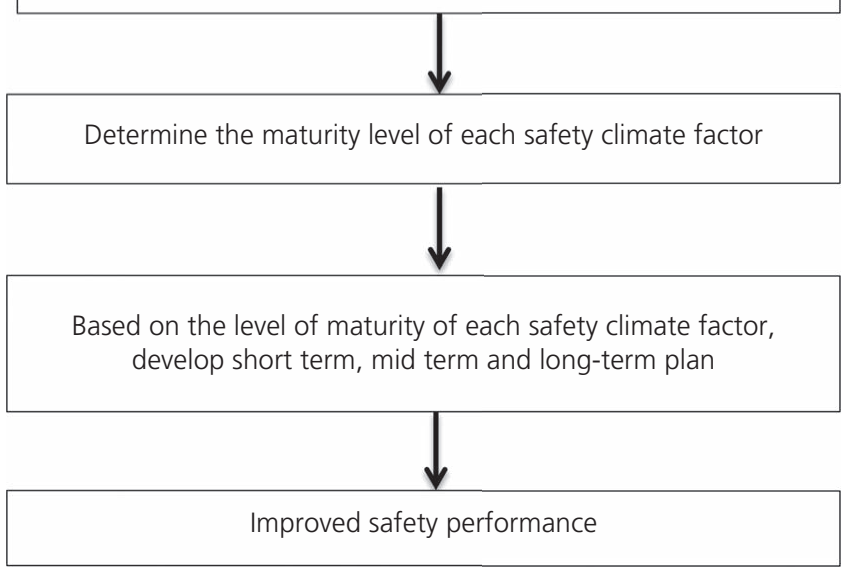

Figure 4. Process of using safety climate to improve safety performance (Umar and Wamuziri, 2016b) low-trust relations may have negative impacts on the effectiveness of safety culture in organisations. The coworker's perceptions of the general standard of the workforce's educations, skills and understanding was one of the six most common elements in safety climate research established by Flin et al. (2000). An improved safety performance cannot be achieved without a well-functioning safety system. This was confirmed by Törner and Pousette (2009) through a qualitative research involving direct line managers and employees' safety agents from a construction project. Trust in the management has been confirmed as a positive indication towards an improved safety result. Mayer et al. (1995) noted that confidence in the management incorporates a willingness to take a risk in a relationship and to be vulnerable to the other party.

Safety is a complex issue, and for an improved safety performance, a variety of approaches can be adopted. For instance, knowing the causes of accidents in a project can be helpful in making strategies to avoid or reduce those causes in similar future projects (Umar and Egbu, 2018). Similarly, Smith et al. (2018) noted that stress and work-family conflict can negatively affect personal protective equipment compliance, loyalty to work safety procedures and safety reporting and communication. Extreme heat stress has a serious impact on a human's physiological responses, which can result in work-related injuries, fatalities and reduced production (Yi and Chan, 2017). In the Gulf region, construction workers can be specifically affected by heat stress, due to body heat generation produced by physically demanding tasks and a hot and humid working environment.

\section{Research aim and methodology}

The overall aim of this research was to find safety climate elements/dimensions that have a high influence on the safety climate in construction in Oman. To identify existing safety climate assessment tools, an internet search using Google Scholar was conducted with the key words of 'safety climate assessment tools' $(N=353000)$ and 'safety climate factors' $(1470000)$. The selected search period was from 1980 to 2017. The selection of assessment tools was kept limited to the tools used in construction, utilities and oil and gas sectors. To narrow the results further, the number of Google citations was used for research-based tools. The tools that were developed by renowned health and safety organisations were also considered. After screening, a total of $13(N=13)$ safety climate assessment tools obtained from this search have been compiled with full details as shown in Table 1 in Appendix 1. Briefly, the number of assessment tools found through the internet search was one in each of the years 1980, 1991, 1997, 2000, 2004, 2005, 2006, 2008 and 2010; there were three assessment tools found in 2011 and one assessment tool in 2017. The number of leading safety climate factors used in these assessment tools was 62 . The result shows that in the first 19 years from 1980 to 1999 , only three safety climate assessment tools were developed. In the next phase of 17 years from 2000 to 2017, the number of safety climate assessment tools was ten. Full details of the safety climate assessment tools used in this article are shown in Appendix 1. 
This leads the authors to proceed with their research and to find which safety climate factors/dimensions will be more relevant to the construction industry in Oman. Apart from this, the authors also wanted to solicit the views of construction professionals in Oman on the relevance of a safety climate approach and how well it is understood in Oman. In order to accomplish this goal, a qualitative method, as opposed to a quantitative method, was employed in this research. Concisely, the difference between these two research methods is given below.

Quantitative research stresses quantification in the data collection and examination. It applies a deducible approach to the connection between theory and research, and stress is kept on the confirmation of theories. The quantitative research method integrates the norms and practices of the natural scientific model and positivism. It views social phenomenon as an outer objective truth (Cooper et al., 2006).

On the other hand, a qualitative research approach stresses words and contexts rather than quantification in data collection (Opdenakker, 2006). It stresses an introductory approach in the relationship between theory and research, and the focus is on the formation of theories. The majority of researchers prefer to incorporate both qualitative and qualitative methods, referred to as a combined research method and highly appreciated in the literature due to certain advantages (Wamuziri, 2013). Since the research presented in this paper is exploratory in nature, a qualitative method was considered as the most suitable method to collect the data. A face-to-face interview method was employed to gather related information. The set of questions used for data collection in this research is presented in Appendix 2.

The interviewees were picked based on a deliberative sampling. Such sampling is critical in nature, and the principles or intention was to interview respondents who were more appropriate to the research questions. This was accomplished by interviewing a total of six top managers from leading construction contractors in Oman. Managers working at the top level with safety responsibilities in construction organisations were considered as the most appropriate people to supply characterisations of the actual world with regard to safety climate factors. The criteria adopted to select the interviewees were that each interviewee should have at least 5 years' experience in Oman; the interviewee's company must be an international company and registered as 'excellent grade' or 'grade one' company with the Tender Board of Oman. The Tender Board of Oman takes care of all government tenders valued at 3 million OMR (US\$7.79 million) or more (TBO, 2018). A brief description of each interviewee is presented here.

(a) Interviewee one: a senior engineer in a construction organisation mainly working in the transportation sector in Oman having more than 20 years of project management experience in the highway sector. The company in Oman was initially established in 1973. (b) Interviewee two: a senior project engineer in a construction organisation working in the housing sector in Oman, with more than 25 years of experience of project management in building sector. The organisation was initially established in 1972 and is currently registered as an excellent grade company in Oman.

(c) Interviewee three: a senior construction manager with more than 10 years of experience in one of the major construction companies with offices in all Gulf Cooperation Council (GCC) countries. The company is $100 \%$ privately owned with more than 1000 employees in Oman. The interviewee is currently working as project director of a highway construction project with an estimated cost of US\$305.90 million.

(d) Interviewee four: a senior construction manager with over 12 years of experience in one of the main construction companies. The organisation was established in 1992 and is currently executing some of the main building projects pertaining to both the government and private sector in Oman. The construction manager interviewed from this organisation is working on a construction project with an estimated cost of US\$60 million.

(e) Interviewee five: a senior contract manager with over 15 years of experience in one of the world's leading consulting organisations, having offices in the USA, Europe and Middle East. The organisation was founded in 1944 and is $100 \%$ owned by the employee stock ownership trust, with total revenues of US $\$ 3 \cdot 2$ billion in 2015.

$(f)$ Interviewee six: a senior design consultant with more than 8 years of experience in one of the leading international consultants operating in the Middle East, Africa, Asia and Europe, with more than 10000 staff. The interviewee is currently involved as design and supervision consultant in some of the megaroad projects in Oman.

Bryman (2015) noted that the use of semistructured interview methods enable the investigator to check the level of understanding that a participant has around a specific issue - generally in more detail than a paper questionnaire - and can be utilised as an effective tool of exploratory evaluation. Similarly, it can be helpful to understand how a participant thinks about a specific topic prior to using a secondary method such as respondent observation and deeper interviewing to collect a lager extent of information. Face-to-face interviews can also be useful to recognise participants whose perspectives may be investigated in more detail through the use of focus groups (Brannen, 2017). The method further allows asking the majority of the questions to respondents in a similar pattern. This makes the process simple for the researcher to repeat and replicate the interview. Overall, such a method of research approach is easy to standardise. Furthermore, it allows researchers to contact acceptable numbers of respondents comfortably and quickly and can collect reliable data (Cooper et al., 2006; Thurman, 2018). There are, however, some weaknesses and limitations in this approach. For instance, Bryman (2015) noted that such methods are timeconsuming if the selected sample group is larger, the reason being that the researcher or their representative is required to be available at 
the time of the face-to-face interview. Similarly, Punch (2013) mentioned that the quality and value of the collected information are deeply dependent on the nature of the questions asked. The pattern of the questionnaire makes it difficult for the researcher to evaluate complicated issues and beliefs. Even where open-ended questions are utilised, the extent of the answers the participant can give turns out to be more restricted than with other qualitative approaches (Brannen, 2017; Cooper et al., 2006).

Notwithstanding these constraints, the six participants in this research proved to be a rich source of useful facts, which can be helpful in further deeper examination in the subject area.

The data gathered through the face-to-face interview approach are assessed, evaluated and presented in the next section.

\section{Results and discussion}

\subsection{Effectiveness of safety climate for safety improvement}

Research conducted by Zohar (1980) shows that there is reconciliation among employees' perceptions concerning the safety climate in their company and that the level of this climate is correlated with safety programme effectiveness as evidenced by safety inspectors. He further suggested that the organisational climate, when operationalised and validated, can be used as a helpful instrument in understanding work-related behaviour. From the discussion with the interviewees, a consensus was observed on the effectiveness of the safety climate approach towards a better safety output. All interviewees agreed that an understanding of the safety climate approach and using appropriate safety climate dimensions and factors is the main key to the effectiveness of the safety climate approach. Interviewees two and three, however, mentioned that safety is something in which responsibility cannot be put only on construction organisations. Interviewee three stressed the importance of safety inspections by external regulatory organisations. He stated that effective health and safety regulations and their implementation across construction organisations are very important for the maximum safety performance. Interviewees four and five mentioned that although safety is everyone's responsibility, poor safety performance and increased number of accidents are not in the interest of contractors as it is they who are affected by this. Overall, all interviewees were in support of the safety climate approach, but since none of them has used this approach, their focus was on other aspects including inspections and implementation of regulations and awareness of improved safety performance among construction organisations.

\subsection{Safety climate factors}

Interviewees were firstly briefed on the different safety climate factors shown in Appendix 1. Their views on safety climate factors were different when asked the question on different dimensions or factors that would need to be considered to achieve a mature safety climate and rich safety culture in construction organisations in Oman. They agreed that construction organisations in Oman need to adopt the approach of improving safety culture and safety climate to improve their safety performance. Interviewee one stated that safety training, management commitment and competence for safety and effective safety communication are the key elements of a rich safety culture and as such need to be considered as safety climate factors. Interviewee two's and interviewee three's views on safety climate factors were almost the same. They noted that personal commitment towards safety has a significant impact on safety outcome; therefore, personal safety commitment and knowledge of safety are some of the important elements that will influence safety culture and safety climate. Interviewee three, however, did mention safety empowerment and stated that workers need to have the right of non-acceptance of risk. Interviewee four highlighted the importance of accountability for safety through active monitoring and enforcing. He stated that safety compliance is important towards a safe work environment, and therefore, there has to be a system that ensures that safety is not to be compromised at any level. The workers must have training on job safety or at least a safety briefing before taking on a specific job or task. Interviewee five stated that the main factor that can lead towards an improved safe workplace is management involvement in safety. How much safety is important to management and how much they are committed towards safety is a key element. Other elements, apart from management commitment, that need to be considered are safety communication on-site, training of workers and motivation and behaviour of workers. He stressed that although personal safety comes first, workers need a level of motivation to ensure coworkers' safety as well, which is very important in achieving a safer working environment. Interviewee six stated that the factors that can lead a construction organisation towards an improved safety performance are related to the individual and the organisation. Individual factors are motivation, behaviour, knowledge and non-acceptance of risk, while organisational factors are commitment and compliance of safety, training, accountability and effective communication of safetyrelated matters.

\subsection{Safety climate assessment tool}

From the literature review, the authors came across different forms of safety climate tools. For instance, the tool proposed by Zohar (1980) has seven organisational dimensions with a fivepoint scale for evaluation. Similarly, Dedobbeleer and Béland (1991) suggested a four-point scale for some factors and a fivepoint scale for other items. The significant item in these tools is, however, the set of factors that were used in these tools for assessment. In this research, an opportunity was given to the interviewees to express their view on the possible format of such an instrument if developed for construction organisations in Oman. All the interviewees agreed that they are not using any such tool for the assessment of their safety climate. Interviewees two and five did mention that they normally use accidents analysis to identify the root causes of accidents and to develop strategies to avoid such accidents in future. Interviewee five 
mentioned that if the accident has taken place because of worker knowledge, then they incorporate the appropriate training to avoid such accidents in the future. All interviewees agreed that leading safety climate factors need to be measured on a scoring scale of 1-5 (strongly agreed-strongly disagreed). Interviewee one stated that there is no need to give an option for neutral in the scoring of any leading safety climate factor and the scale can be from 1 to 4 (strongly agreed-strongly disagreed). Interviewee three mentioned that such a questionnaire needs to be prepared in multiple languages in order to serve the diverse construction industry in Oman effectively. Interviewee six mentioned the use of technology tools for using such a questionnaire, rather than a paper-based approach.

\subsection{Effectiveness of safety climate assessment tool}

Although safety climate assessment tools are successfully used in different industries including construction worldwide, the authors were interested to know the views of construction industry professionals in Oman of their effectiveness (NRCWE, 2018). Research carried out by Dedobbeleer and Béland (1991) claims that the results of the safety climate assessment can help in the development of safety policies in an organisation. Neal et al. (2000), while examining the results of general organisational climate on safety climate and safety performance, noted that general organisational climate had a powerful impact on safety climate. They further explained the significance of both organisational climate and safety climate on individual safety practice. Kines et al. (2011) noted that there is increasing indication that safety climate is a precursor of safety performance. All interviewees agreed that a safety climate assessment tool which will allow construction organisations in Oman to assess their level of safety culture and safety climate will be helpful to improve the safety performance of construction organisations. Interviewee two mentioned that construction organisations should have sufficient knowledge of such tools before they use it in order to use it properly and get full benefits from it. Interviewees one, three and five stated that it is possible for all sizes of construction organisations to prepare their plans for safety improvement through the results of the safety climate assessment; however, small construction organisations can face financial and technical issues because of their capacity to implement such plans. Small construction organisations will need to have some external support to implement such plans to achieve the required level of maturity for any safety climate dimension. Factors that differentiate the safety performance of small and medium enterprises (SMEs) from larger organisations have attracted the attention of many researchers, including financial capacity as identified by the interviewees. For instance, Masi et al. (2014) stated that SMEs have less financial and human assets at their disposal. Thus, under such conditions of economic uncertainty, owners of SMEs are afraid to invest time and resources on problems that do not arise on a regular basis, and this would certainly include safety and health issues (Agumba and Haupt, 2012; MacEachen et al., 2010).

\section{Conclusion}

This article discusses the concept of using of the safety climate approach to enhance safety performance in construction. The third wave of safety, commonly known as the management system age (1980s), extended the focus to include safety culture and drive the approach of safety climate. The literature review indicates that there is an increasing confirmation of safety climate as a precursor of safety performance. Specific criteria have been used to identify the relevant safety climate factors, resulting in 62 factors spanning over a period of 37 years from 1980 to 2017. The safety climate approach and the identified factors were discussed with the selected group of construction professionals working in Oman. The results of face-to-face interviews with construction professionals working in Oman show that their organisations are currently not using this approach. The overall aim of this study was to find safety climate elements/dimensions that will have more influence on the safety climate in construction in Oman. Interviewees identified several factors that could have a high level of influence on safety climate, including management commitment; alignment and integration of safety as a value; accountability across the board; supervisory management; empowerment and involvement of workers; improvement of communication; and training and education. This research is based on the views of six construction professionals working as top managers in their construction organisation. The construction team of any organisation is composed of managers, supervisors, skilled workers and labourers; therefore, their views on the use of safety climate approach and different factors would add advantage and a wider acceptability. Such research will help develop a safety climate assessment tool that will be more relevant to the Omani construction industry. It is anticipated that the similarity between GCC construction industries will allow such a tool to be acceptable in all member countries.

\section{Acknowledgements}

The authors acknowledge the support in proofreading and editing provided by Dr Uma GRajan, English language lecturer from the Centre for Language and Foundation Studies, A'Sharqiyah University, Oman. 


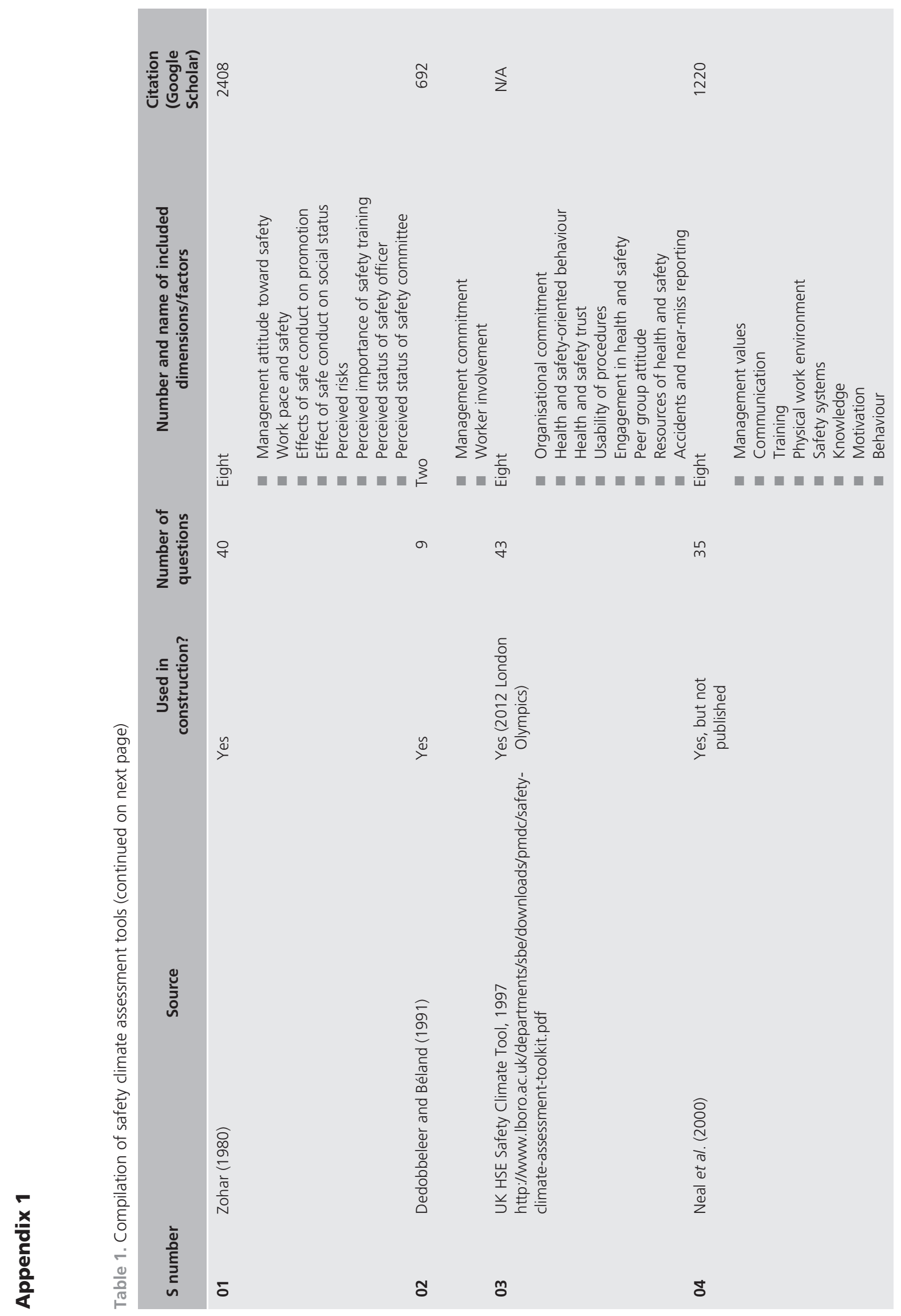




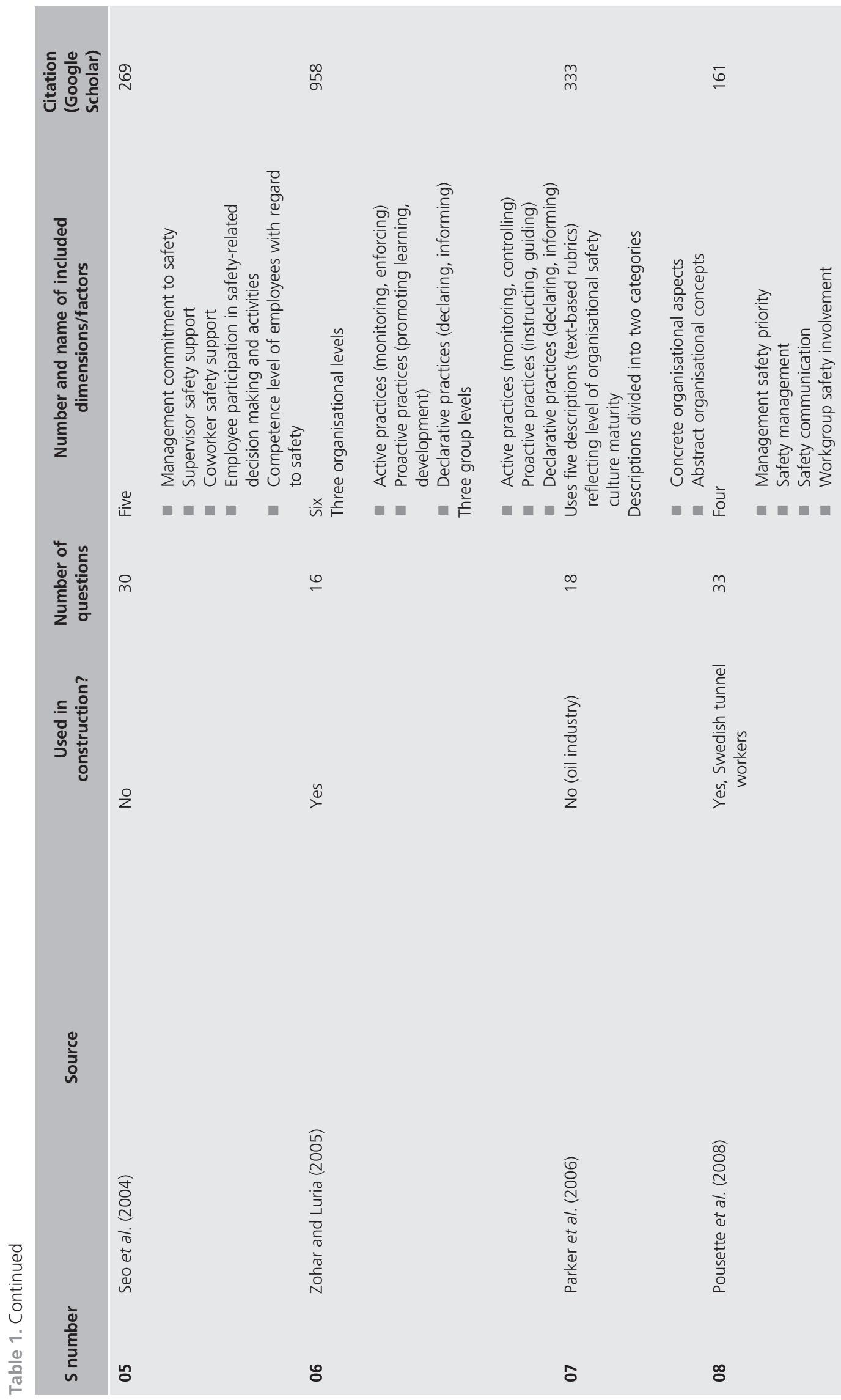




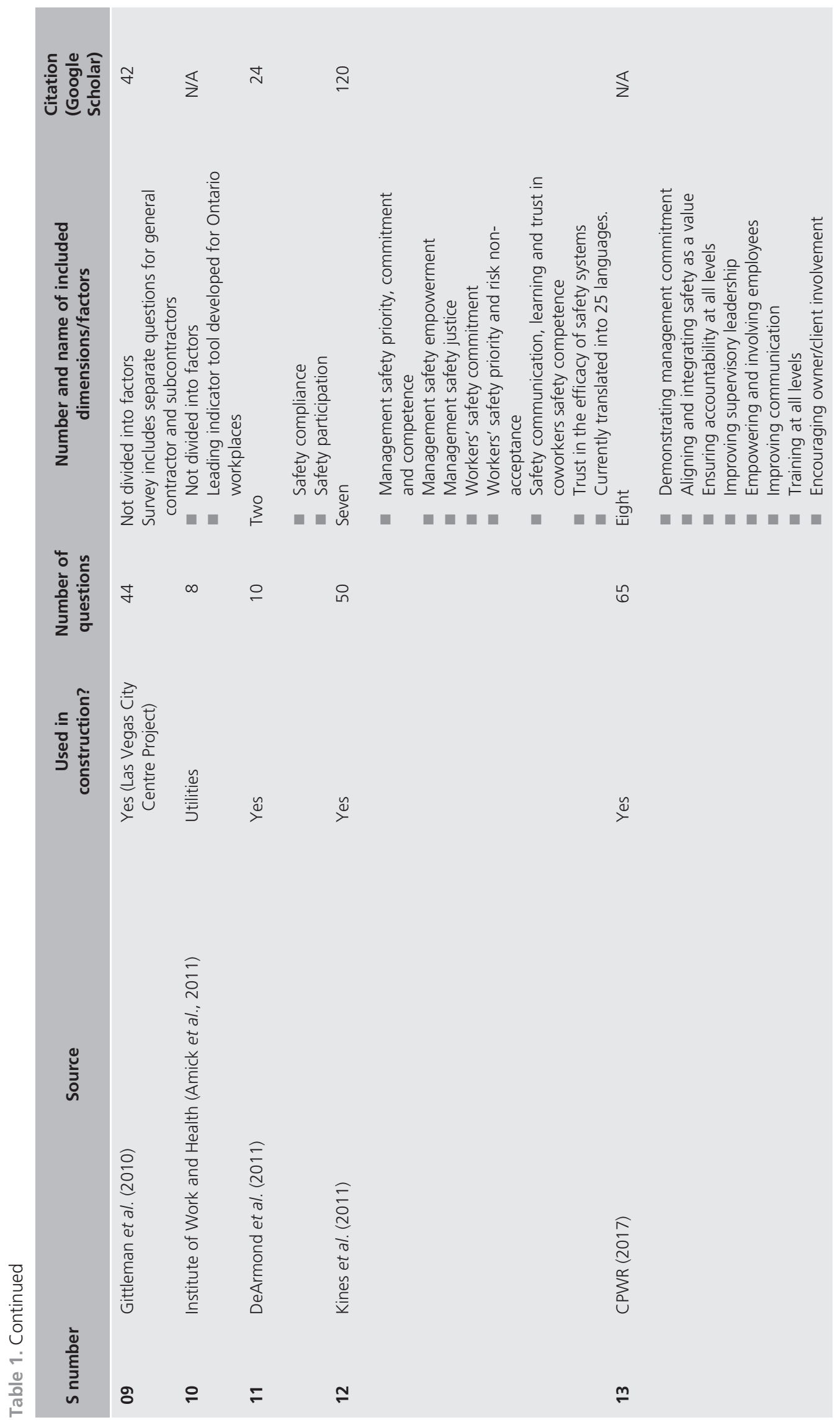




\section{Appendix 2. Semistructured interview questions}

1. In recent years, the awareness of the importance for safety performance of organisational, managerial and social factors, has increased. Safety climate is a subset of organisational climate, offers a route for safety management, complementing the often predominant engineering approach. What is your opinion on the effectiveness of this new approach to enhancing safety performance in construction organisations?

2. Most organisations use records of their health and safety performance as an indication of the effectiveness of their health and safety management and systems. Do you think that an understanding of the safety climate dimensions or factors can be useful in improving the safety performance of construction organisation?

3. There is a generally held view by researchers that a mature safety climate can help in building a rich safety culture, and there are different dimensions or factors identified which influence safety climate. What is your view on different dimensions or factors that would need to be considered to achieve a mature safety climate and rich safety culture in a construction organisation in Oman?

4. Researchers and practitioners have identified safety culture and safety climate as key to reducing injuries, illnesses and fatalities on construction worksites. Many construction contractors are trying to improve these indicators as a way to move closer to a goal of achieving zero-injury worksites. Do you think construction organisations in Oman need to adopt the concept of improving safety culture and safety climate to improve their safety performance?

5. Safety climate of a construction project or construction organisation can be assessed by means of quantitative, psychometric questionnaire surveys, so-called safety climate scales, measuring the shared perceptions/opinions of a group of workers on certain safety-related dimensions or factors. The outcome of such safety climate scales is regarded as a predictor or indicator of safety performance. What is your opinion on such a tool? Does your organisation use such a tool to assess the safety climate?

6. The leading safety climate dimensions or factors can be measured among different categories of staff working in construction organisation or in a project undertaken by the construction organisation on a scoring scale of 1-5 (strongly agreed-strongly disagreed). The results will reflect the safety climate of the organisation or safety climate of the specific project. After the assessment of safety climate leading dimensions or factors, construction organisations will be able to identify and prioritize the weak area for improvement. What could be the possible format if we want to develop a safety climate assessment tool for construction organisation in Oman?

7. Do you think that the assessment of the safety climate will help the decision-making unit (DMU) of construction organisations to develop different plans to achieve the required level of maturity of safety climate?
8. Different sizes of construction organisations (small, medium and large) have different levels of resources and competencies. In your view, how will different sizes of construction organisation benefit from adopting the concept improving of safety performance through safety climate?

\section{REFERENCES}

Agumba JN and Haupt TC (2012) Identification of health and safety performance improvement indicators for small and medium construction enterprises: a Delphi consensus study. Mediterranean Journal of Social Sciences 3(3): 545-557, https://doi.org/10.5901/ mjss.2012.v3n3p545.

AIChE (American Institute of Chemical Engineers) (2012) Safety Culture What Is at Stake? AIChE, New York, NY, USA. See http://www.aiche. org/ccps/topics/elements-process-safety/commitment-process-safety/ process-safetyculture/building-safety-culture-tool-kit/what-is-at-stake (accessed 01/12/2017).

Amick B, Farquhar A, Grant K et al. (2011) Benchmarking Organizational Leading Indicators for the Prevention and Management of Injuries and Illnesses: Final Report. Institute for Work and Health, Toronto, ON, Canada. See http:/www.iwh.on.ca/benchmarking-organizationalleading-indicators (accessed 30/05/2018).

Bergh M, Shahriari M and Kines P (2013) Occupational safety climate and shift work. Chemical Engineering Transactions 31: 403-408, https:// doi.org/10.3303/CET1331068.

Brannen J (ed.) (2017) Mixing Methods: Qualitative and Quantitative Research. Routledge, Abingdon, UK.

Bryman A (2015) Social Research Methods. Oxford University Press, Oxford, UK.

Clarke S (2000) Safety culture: underspecified and overrated? International Journal of Management Reviews 2(1): 65-90, https://doi. org/10.1111/1468-2370.00031.

Clarke S (2006) Contrasting perceptual, attitudinal and dispositional approaches to accident involvement in the workplace. Safety Science 44(6): 537-550, https://doi.org/10.1016/j.ssci.2005.12.001.

Clarke S (2010) An integrative model of safety climate: linking psychological climate and work attitudes to individual safety outcomes using meta-analysis. Journal of Occupational and Organizational Psychology 83(3): 553-578, https://doi.org/10.1348/ 096317909 X452122.

Clarke S and Ward K (2006) The role of leader influence tactics and safety climate in engaging employees' safety participation. Risk Analysis 26(5): 1175-1185, https://doi.org/10.1111/j.1539-6924.2006.00824.x.

Cooper DR, Schindler PS and Sun J (2006) Business Research Methods. McGraw-Hill Irwin, New York, NY, USA, vol. 9.

Cox S and Cox T (1991) The structure of employee attitudes to safety: a European example. Work and Stress 5(2): 93-106, https://doi.org/10. 1080/02678379108257007.

Cox S, Jones B and Collinson D (2006) Trust relations in high-reliability organizations. Risk Analysis 26(5): 1123-1138, https://doi.org/10.1111/ j.1539-6924.2006.00820.x.

CPWR (Center for Construction Research and Training) (2013) Safety Culture and Climate in Construction. CPWR, Silver Spring, MD, USA. See https://www.cpwr.com/sites/default/files/CPWR_Safety_ Culture Final Report.pdf (accessed 01/02/2018).

CPWR (2014) Jobsite Safety Climate 2014. CPWR, Silver Spring, MD, USA CPWR (2017) Strengthening Jobsite Safety Climate by Using and Improving Leading Indicators. CPWR, Silver Spring, MD, USA. See http://www.cpwr.com/safety-culture/strengthening-jobsite-safetyclimate (accessed 30/05/2018).

DeArmond S, Smith AE, Wilson CL, Chen PY and Cigularov KP (2011) Individual safety performance in the construction industry: development and validation of two short scales. Accident Analysis \& Prevention 43(3): 948-954, https://doi.org/10.1016/j.aap.2010.11.020. 
Dedobbeleer N and Béland F (1991) A safety climate measure for construction sites. Journal of Safety Research 22(2): 97-103, https:// doi.org/10.1016/0022-4375(91)90017-P.

Deloitte (2015) Deloitte GCC Powers of Construction 2015 Construction - The Economic Barometer for the Region. Deloitte, Beirut, Lebanon. See https://business-humanrights.org/sites/default/files/documents/ Deloitte-GCC-Powers-of-Construction-2015.pdf (accessed 15/10/ 2016).

Dube A, Freeman E and Reich M (2010) Employee Replacement Costs. Institute for Research on Labour and Employment, Berkeley, CA, USA. See http://irle.berkeley.edu/files/2010/Employee-ReplacementCosts.pdf (accessed 01/02/2018).

Duranton G (2015) Growing through cities in developing countries. World Bank Research Observer 30(1): 39-73, https://doi.org/10.1093/ wbro/lku006.

Flin R, Mearns K, O'Connor P and Bryden R (2000) Measuring safety climate: identifying the common features. Safety Science 34(1-3): 177-192, https://doi.org/10.1016/S0925-7535(00)00012-6.

Gittleman JL, Gardner PC, Haile A et al. (2010) [Case Study] CityCenter and Cosmopolitan Construction Projects, Las Vegas, Nevada: Lessons learned from the use of multiple sources and mixed methods in a safety needs assessment. Journal of Safety Research 41(3): 263-281, https://doi.org/10.1016/j.jsr.2010.04.004.

Glendon Al and Stanton NA (2000) Perspectives on safety culture. Safety Science 34(1-3): 193-214, https://doi.org/10.1016/S0925-7535(00) 00013-8.

Hale AR (2000) Culture's confusions. Safety Science 34(1-3): 1-14, https://doi.org/10.1016/S0925-7535(00)00003-5.

Hale AR and Hovden J (1998) Management and culture: the third age of safety - a review of approaches to organizational aspects of safety, health and environment. In Occupational Injury: Risk, Prevention and Intervention (Feyer AM and Williamson A (eds)). CRC Press, Boca Raton, FL, USA, pp. 129-227.

Hofmann DA and Morgeson FP (1999) Safety-related behaviour as a social exchange: the role of perceived organizational support and leadermember exchange. Journal of Applied Psychology 84(2): 286-296.

Ikpe E, Hammon F and Oloke D (2012) Cost-benefit analysis for accident prevention in construction projects. Journal of Construction Engineering Management 138(8): 991-998, https://doi.org/10.1061/ (ASCE)CO.1943-7862.0000496.

ILO (International Labour Organization) (2015) Construction: A Hazardous Work. ILO, Geneva, Switzerland. See http://www.ilo.org safework/areasofwork/hazardous-work/WCMS_356576/lang-en/index. htm (accessed 11/03/2017).

INSAG (International Nuclear Safety Advisory Group) (1992) INSAG-7 The Chernobyl Accident: Updating of INSAG-1. International Atomic Energy Agency, Vienna, Austria, INSAG Safety Series No. 75INSAG-7. See https://www-pub.iaea.org/MTCD/publications/PDF/ Pub913e web.pdf (accessed 14/01/2018).

James LR and Jones AP (1974) Organizational climate: a review of theory and research. Psychological Bulletin 81: 1098-1112.

Jeffcott S, Pidgeon N, Weyman A and Walls J (2006) Risk, trust, and safety culture in UK train operating companies. Risk Analysis 26(5): 1105-1121, https://doi.org/10.1111/j.1539-6924.2006.00819.x.

Kines P, Lappalainen J, Mikkelsen KL et al. (2011) Nordic Safety Climate Questionnaire (NOSACQ-50): a new tool for diagnosing occupational safety climate. International Journal of Industrial Ergonomics 41(6): 634-646, https://doi.org/10.1016/j.ergon.2011.08.004.

Kuenzi M and Schminke M (2009) Assembling fragments into a lens: a review, critique, and proposed research agenda for the organisational work climate literature. Journal of Management 35(3): 634-717, https://doi.org/10.1177/0149206308330559.

Lancaster R, Ward R, Talbot P and Brazier A (2003) Costs of Compliance with Health and Safety Regulations in Small and Medium Enterprises (SME). Health and Safety Executive, London, UK, HSE Research Rep. 174.
Larsson S, Pousette A and Törner M (2008) Psychological climate and safety in the construction industry-mediated influence on safety behaviour. Safety Science 46(3): 405-412.

MacEachen E, Kosny A, Scott-Dixon K et al. (2010) Workplace health understandings and processes in small businesses: a systematic review of the qualitative literature. Journal of Occupational Rehabilitation 20(2): 180-198, https://doi.org/10.1007/s10926-009-9227-7.

Masi D, Cagno E and Micheli GJL (2014) Developing, implementing and evaluating OSH interventions in SMEs: a pilot, exploratory study. International Journal of Occupational Safety and Ergonomics 20(3): 385-405, https://doi.org/10.1080/10803548.2014.11077059.

Mayer RC, Davis JH and Schoorman FD (1995) An integrative model of organizational trust. Academy of Management Review 20(3): 709-734.

NCSI (National Centre for Statistics and Information) (2015) National Centre for Statistics and Information, Oman Statistical Year Book. NCSI, Muscat, Oman, issue 43. See https://www.ncsi.gov.om/Elibrary/ LibraryContentDoc/ben_Statistical_Year_Book_2015_740d0da1-01d24f42-a159-6102a49ecf59.pdf (accessed 15/10/2016).

NCSI (2017) Oman: Statistical Year Book. NCSI, Muscat, Oman, issue 45. See https://www.ncsi.gov.om/Elibrary/LibraryContentDoc/ bar_Statistical\%20Year\%20Book\%202017_c2111831-e13a-4075-bf7bc4b5516e1028.pdf (accessed 01/02/2018).

Neal A and Griffin MA (2006) A study of the lagged relationships among safety climate, safety motivation, safety behavior, and accidents at the individual and group levels. Journal of Applied Psychology 91(4): 946-953.

Neal A, Griffin MA and Hart PM (2000) The impact of organizational climate on safety climate and individual behavior. Safety Science 34(1-3): 99-109, https://doi.org/10.1016/S0925-7535(00)00008-4.

Nielsen KJ and Mikkelsen KL (2007) Predictive factors for self-reported occupational injuries at 3 manufacturing plants. Safety Science Monitor 11(2): 1-9.

NRCWE (National Research Centre for the Working Environment) (2018) The Nordic Occupational Safety Climate Questionnaire- NOSACQ-50 Database. NRCWE, Copenhagen, Denmark. See http://www. arbejdsmiljoforskning.dk/en/publikationer/spoergeskemaer/nosacq-50/ nosacq-50-database (accessed 01/02/2018).

OB (Oman Budget) (2017) Oman - 2017 Budget Highlights. Klynveld Peat Marwick Goerdeler, Muscat, Oman. See https://assets.kpmg.com/ content/dam/kpmg/om/pdf/Oman_budget_2017.pdf (accessed 01/02/ 2018).

ONS (Office for National Statistics) (2017) Construction statistics: Number 18, 2017th edn. ONS, London, UK. See https://www.ons.gov. $\mathrm{uk} /$ businessindustryandtrade/constructionindustry/articles/ constructionstatistics/number182017edition (accessed 01/02/2018).

Opdenakker R (2006) Advantages and disadvantages of four interview techniques in qualitative research. Forum Qualitative Sozialforschung/ Forum: Qualitative Social Research 7(4): 1-13, https://doi.org/ 10. 17169/fqs-7.4.175.

OSC (Oman Society of Contractors) (2016a) Annual General Meeting report, 2016. Oman Society of Contractors, Muscat, Oman.

OSC (2016b) Annual General Meeting: Distribution of Expatriate in Construction Organizations of Oman. Oman Society of Contractors, Muscat, Oman.

OSHA (Occupational Health and Safety Administration) (2014) Statistics 2014. OSHA, Washington, DC, USA. See https://www.osha.gov/ oshstats/index.html (accessed 22/01/2017).

Parker D, Lawrie M and Hudson P (2006) A framework for understanding the development of organisational safety culture. Safety Science 44(6): 551-562, https://doi.org/10.1016/j.ssci.2005.10.004.

Pousette A, Larsson S and Törner M (2008) Safety climate crossvalidation, strength and prediction of safety behaviour. Safety Science 46(3): 398-404, https://doi.org/10.1016/j.ssci.2007.06.016.

Punch KF (2013) Introduction to Social Research: Quantitative and Qualitative Approaches. Sage, Thousand Oaks, CA, USA. 
Management, Procurement and Law

Volume 171 Issue MP6
Perceptions on safety climate: a case

study in the Omani construction industry

Umar and Egbu
Seo DC, Torabi MR, Blair EH and Ellis NT (2004) A cross-validation of safety climate scale using confirmatory factor analytic approach. Journal of Safety Research 35(4): 427-445, https://doi.org/10.1016/j. jsr.2004.04.006

SHJ (Statistical Handbook of Japan) (2017) Manufacturing and construction. Statistical Handbook of Japan. Statistics Bureau, Ministry of Internal Affairs and Communication, Tokyo, Japan. See http://www.stat.go.jp/ english/data/handbook/pdf/2017all.pdf (accessed 01/02/2018).

Smith TD, Hughes K, DeJoy DM and Dyal MA (2018) Assessment of relationships between work stress, work-family conflict, burnout and firefighter safety behavior outcomes. Safety Science 103: 287-292, https://doi.org/10.1016/j.ssci.2017.12.005.

Tang SL, Ying KC, Chan WY and Chan YL (2004) Impact of social safety investments social costs of construction accidents. Journal of Construction Management and Economics 22(9): 937-946, https://doi. org/10.1080/0144619042000226315.

TBO (Tender Board of Oman) (2018) International Registered Companies. TBO, Muscat, Oman. See https://etendering.tenderboard.gov.om/product/ ReportAction?eventFlag=SearchVendPublic (accessed 04/02/2018).

Törner M and Pousette A (2009) Safety in construction-a comprehensive description of the characteristics of high safety standards in construction work, from the combined perspective of supervisors and experienced workers. Journal of Safety Research 40(6): 399-409.

Thurman N (2018) Mixed Methods Communication Research: Combining Qualitative and Quantitative Approaches in the Study of Online Journalism. Sage, Thousand Oaks, CA, USA.

Umar T (2016) Briefing: Cost of accidents in the construction industry of Oman. Proceedings of the Institution of Civil Engineers - Municipal Engineer 170(2): 68-73, https://doi.org/10.1680/jmuen.16.00032.

Umar T and Egbu C (2018) Causes of construction accidents in Oman. Middle East Journal of Management 5(1): 21-33, https://doi.org/10. 1504/MEJM.2018.088725.

Umar T and Wamuziri SC (2016a) A review of construction safety, challenges and opportunities - Oman perspective. In Proceedings of 5th World Construction Symposium 2016 (Sandanayake YG, Karunasena GI and Ramachandra T (eds)). University of Moratuwa, Colombo, Sri Lanka, pp. 14-22.

Umar T and Wamuziri S (2016b) Briefing: Using 'safety climate factors' to improve construction safety. Proceedings of the Institution of Civil Engineers - Municipal Engineer 170(2): 65-67, https://doi.org/10. 1680/jmuen.16.00020.

Umar T, Egbu C, Wamuzir S and Honnurvali MS (2018) Occupational safety and health regulations in Oman. Proceedings of the Institution of Civil Engineers - Management, Procurement and Law, https://doi. org/10.1680/jmapl.18.00007.

Wallace JC, Popp E and Mondore S (2006) Safety climate as a mediator between foundation climates and occupational accidents: a group-level investigation. Journal of Applied Psychology 91(3): 681-688, https:// doi.org/10.1037/0021-9010.91.3.681.

Wamuziri S (2013) Factors that influence safety culture in construction. Proceedings of the Institution of Civil Engineers - Management, Procurement and Law 166(5): 219-231, https://doi.org/10.1680/mpal. 12.00023.

Yi W and Chan AP (2017) Effects of heat stress on construction labour productivity in Hong Kong: a case study of rebar workers. International Journal of Environmental Research and Public Health 14(9): 1-14, https://doi.org/10.3390/ijerph14091055.

Zohar D (1980) Safety climate in industrial organizations: theoretical and applied implications. Journal of Applied Psychology 65(1): 96-102, https://doi.org/10.1037/0021-9010.65.1.96.

Zohar D (2002) Modifying supervisory practices to improve subunit safety: a leadership-based intervention model. Journal of Applied Psychology 87(1): 156-163, https://doi.org/10.1037/0021-9010.87.1. 156.

Zohar D and Luria G (2005) A multilevel model of safety climate: crosslevel relationships between organisation and group-level climates. Journal of Applied Psychology 90(4): 616-628, https://doi.org/10. 1037/0021-9010.90.4.616.

\section{How can you contribute?}

To discuss this paper, please email up to 500 words to the editor at journals@ice.org.uk. Your contribution will be forwarded to the author(s) for a reply and, if considered appropriate by the editorial board, it will be published as discussion in a future issue of the journal.

Proceedings journals rely entirely on contributions from the civil engineering profession (and allied disciplines). Information about how to submit your paper online is available at www.icevirtuallibrary.com/page/authors, where you will also find detailed author guidelines. 